\title{
Kinetics of Supercritical Fluid Extraction of Ethanol from Aqueous Solution
}

\author{
CLIFFORD Y. TAI AND SHENG-YAN WU \\ Department of Chemical Engineering, National Taiwan University, \\ Taipei, Taiwan
}

\begin{abstract}
A $1.3 \mathrm{dm}^{3}$ high-pressure vessel was used to extract ethanol from aqueous solution of $10 w t \%$ using supercritical carbon dioxide as a solvent. Experiments were carried out in a semibatch mode. A mathematical model based on the two-film theory was derived for estimating the over all mass transfer coefficient. The effects of operating variables, including pressure, $\mathrm{CO}_{2}$ superficial velocity, and agitation rate, on the mass transfer coefficient were investigated. In general, the mass transfer coefficient increased with increasing pressure, $\mathrm{CO}_{2}$ superficial velocity, and agitation rate. The concentration of ethanol recovered in the collector after 180 minutes reached $50 \mathrm{wt} \%$, starting with a feed of $10 \mathrm{wt} \%$ ethanol.
\end{abstract}

Keywords Supercritical fluid extraction; Ethanol; Stirred tank; Mass transfer coefficient

\section{Introduction}

Since the energy shortage of the early 1970s, alternatives to energy-intensive separation techniques, such as evaporation and distillation, have been needed for many industrial processes. The recovery of ethanol from a fermented aqueous solution is a typical example. Thus, the extraction of ethanol from water using supercritical fluids has become a popular research topic. A primary goal of such research is to break the ethanol-water azeotrope of $95.5 \mathrm{wt} \%$ ethanol. Even if this goal is not achieved, demonstration of a less energy-intensive process to replace conventional distillation for concentrating ethanol is still of interest to the process industry.

In the 1980s, extensive data on the carbon dioxide/ethanol/water system over a wide range of ethanol concentrations, temperatures, and pressures were published. These data were analyzed by McHugh and Krukonis (1986), who showed that the conditions of extraction, i.e., pressure ranging from 975 to 3000 psi and temperature ranging from $20^{\circ}$ to $65^{\circ} \mathrm{C}$, do not significantly affect the level of extractability achieved. On the other hand, the selectivity of carbon dioxide for ethanol from an ethanol-water mixture is quite high. However, there is an upper limit of the ethanol concentration at around $90 \mathrm{wt} \%$.

One of the advantages of using supercritical carbon dioxide $\left(\mathrm{SC} \mathrm{CO}_{2}\right)$ as an extraction solvent lies in its mass transport properties. Supercritical carbon dioxide has a liquid-like density, which results in a high level of solubility compared with that of a gas, and a gas-like viscosity, which usually results in a high mass transfer

Address correspondence to Clifford Y. Tai, Department of Chemical Engineering, National Taiwan University, Taipei, Taiwan 106. E-mail: cytai@ntu.edu.tw 
coefficient compared with that of a liquid. In addition, the diffusivity of solute in supercritical fluids is generally higher than that in liquids. Therefore, supercritical carbon dioxide seems to be an ideal solvent for extraction. Furthermore, the non toxicity of carbon dioxide makes it a perfect solvent for the extraction of ethanol from alcoholic beverages in order to obtain low-alcohol drinks. For this purpose, liquid membrane (Etuk and Murray, 1990) and gas stripping techniques (Liu and Hsu, 1990) have been studied.

In spite of the advantages of this promising technology, there have been few studies on the mass transfer of supercritical systems. Only a few experiments were performed using a packed bed (Tan et al., 1988; Puiggené et al., 1997; Bernard et al., 1991; Riha and Brunner, 2000). Recently, Tai et al. (2000) studied the extraction kinetics of zinc ion using supercritical $\mathrm{CO}_{2}$ in a stirred tank. A similar study may be of interest to the chemical industry. For example, ethanol fermentation may be performed in a stirred tank reactor, and in situ ethanol extraction using $\mathrm{SC}^{\mathrm{CO}_{2}}$ may reduce the ethanol toxicity to microorganisms and the cost of purification. For design purposes, this research investigated the effects of operating variables on the mass transfer rate of supercritical $\mathrm{CO}_{2}$ extraction performed in a $1.3 \mathrm{dm}^{3}$ stirred vessel.

\section{Kinetic Model for Estimating the Mass-Transfer Coefficient}

The mass transfer between phases in the extraction process of ethanol from water conducted in a stirred vessel is shown in Figure 1. The operation was performed in a semibatch mode; i.e., the aqueous ethanol solution was charged at the beginning of an experiment, while supercritical $\mathrm{CO}_{2}$ flowed continuously throughout a run.
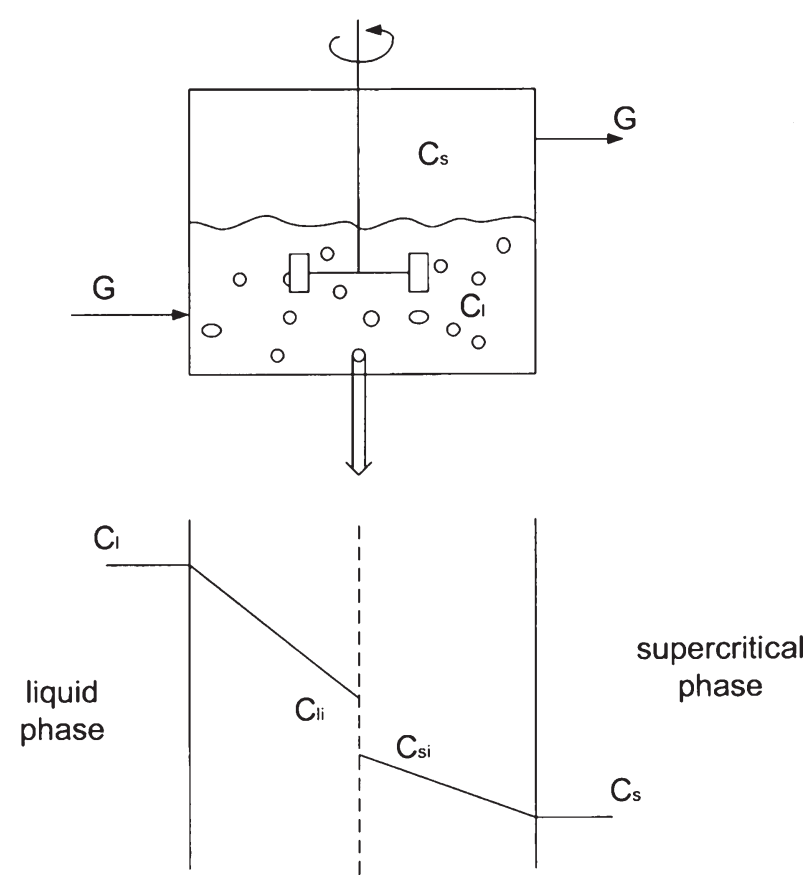

Figure 1. Mass transfer based on the two-film theory for ethanol extraction in a stirred vessel. 
When an impeller was used to agitate the fluids, coarse droplets of $\mathrm{SC} \mathrm{CO}_{2}$, which could be seen through the view port of the extraction vessel, were suspended in the aqueous phase, thus increasing the interfacial area for mass transfer and the extraction efficiency. Since the $\mathrm{SC} \mathrm{CO}_{2}$ was purged continuously, the ethanol concentration of the supercritical phase increased slowly, and the depletion rate of ethanol in the water phase was not high, the two-film theory model was roughly applied. Although the real transport process is more complicated, the simplified model provided a quick way to estimate the mass transfer coefficient and identify important operating variables. In fact, the two-film theory was previously used to interpret mercury extraction kinetics (Larson and Wiencek, 1993) and zinc extraction kinetics (Tai et al., 2000) in a stirred tank.

Assuming that the two-film theory is applied, the mass balance of ethanol in supercritical phase can be written as

$$
\begin{aligned}
V_{s} \frac{d C_{s}}{d t} & =-G C_{s}+V_{l} K_{s} a\left(C_{s}^{*}-C_{s}\right) \\
& =-G C_{s}+V_{l} K_{s} a\left(m C_{l}-C_{s}\right)
\end{aligned}
$$

where $C_{s}^{*}\left(=m C_{l}\right)$ is the concentration of the supercritical phase that would be in equilibrium with the liquid phase concentration, and $K_{s} a$ is the mass transfer coefficient. The values of $m$ were determined in this experiment at $50^{\circ} \mathrm{C}$, and were $0.1778,0.1610$, and 0.1251 for the pressures of $15.3,13.6$, and $10.2 \mathrm{MPa}$, respectively. The above equation has the following initial condition:

$$
C_{s}=0 \text { at } t=0
$$

On the other hand, the mass balance of ethanol in the liquid phase is

$$
\frac{d C_{l}}{d t}=-K_{s} a\left(m C_{l}-C_{s}\right)
$$

with the following initial concentration:

$$
C_{l}=C_{l 0} \text { at } t=0
$$

The above equations can be solved using the Laplace transform method. Let $s$ be the Laplace variable; Equations (2) and (4) are transformed into the following equations:

$$
V_{s} s C_{s}(s)=-G C_{s}(s)+V_{l} K_{s} a\left[m C_{l}(s)-C_{s}(s)\right]
$$

and

$$
s C_{l}(s)-C_{l 0}=-K_{s} a\left[m C_{l}(s)-C_{s}(s)\right]
$$

Rearranging Equation (6), we have

$$
C_{s}(s)=\frac{V_{l} K_{s} a m C_{l}}{V_{s} s+G+V_{l} K_{s} a}
$$

Then Equation (8) can be substituted into Equation (7) to obtain

$$
C_{l}(s)=\frac{(s+A) C_{l 0}}{s^{2}+q_{1} s+q_{2}}
$$


where

$$
\begin{gathered}
A=\frac{G}{V_{s}}+\frac{V_{l}}{V_{s}} K_{s} a \\
q_{1}=K_{s} a m+\frac{G}{V_{s}}+\frac{V_{l}}{V_{s}} K_{s} a \\
q_{2}=K_{s} a m G / V_{s}
\end{gathered}
$$

Therefore,

$$
C_{l}=C_{l 0}\left[\beta_{1} \exp \left(\alpha_{1} t\right)+\beta_{2} \exp \left(\alpha_{2} t\right)\right]
$$

where

$$
\begin{gathered}
\beta_{1}=\frac{\alpha_{1}+A}{\alpha_{1}-\alpha_{2}} \\
\beta_{2}=\frac{\alpha_{2}+A}{\alpha_{2}-\alpha_{1}} \\
\alpha_{1}=\frac{-q_{1}+\sqrt{q_{1}^{2}-4 q_{2}}}{2} \\
\alpha_{2}=\frac{-q_{1}-\sqrt{q_{1}^{2}-4 q_{2}}}{2}
\end{gathered}
$$
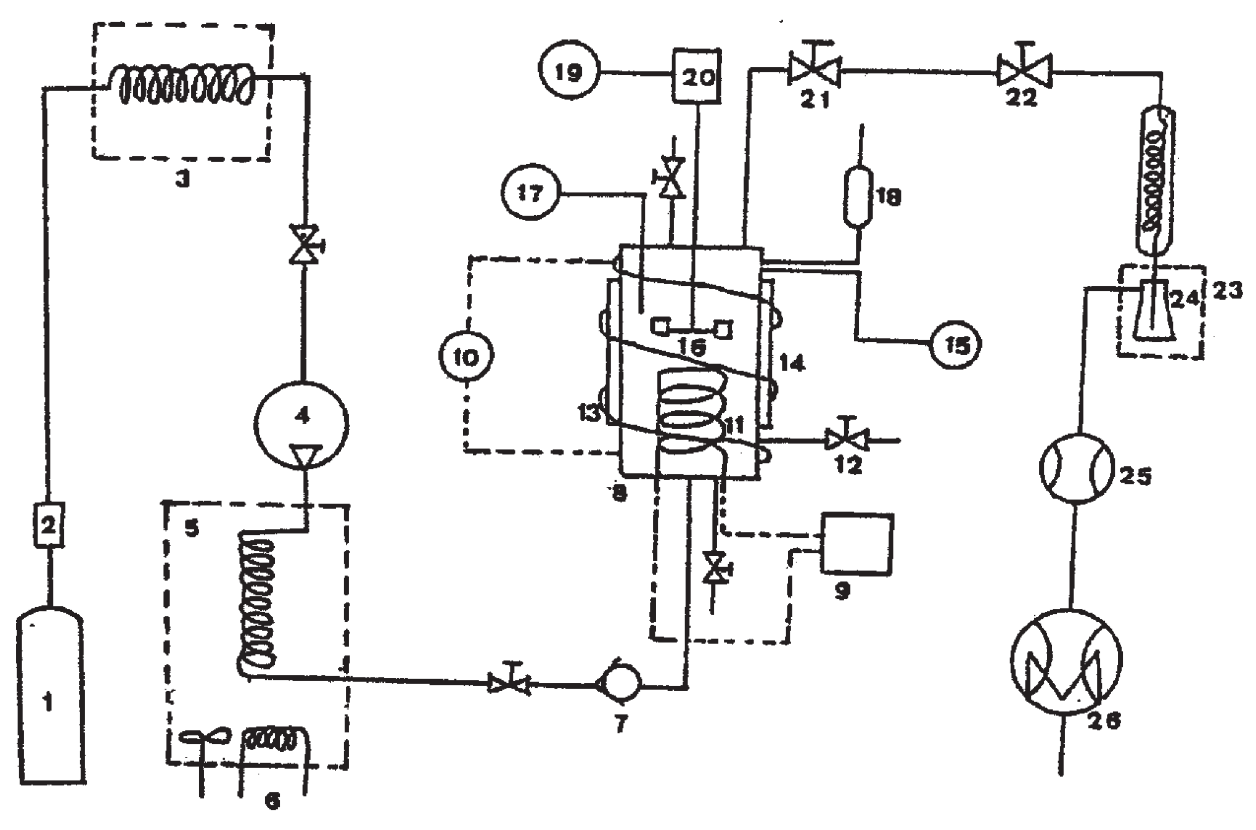

Figure 2. Flow diagram of the ethanol extraction process: 1. $\mathrm{CO}_{2}$ cylinder, 2. filter, 3. refrigerator, 4. mini pump, 5. preheater, 6. heater, 7. check value, 8. extractor, 9. voltage controller, 10. voltage controller, 11. coil, 12. sampling valve, 13. heating tape, 14. view port, 15. pressure gauge, 16. paddle, 17. temperature indicator, 18. safety valve, 19. tachometer, 20. motor, 21. ball valve, 22. metering valve, 23 . cold trap, 24. collector, 25 . rotameter, 26. dry test meter. 
Since $\alpha_{1}$ and $\alpha_{2}$ are smaller than zero, and since $\alpha_{1}>\alpha_{2}$, the value of $\exp \left(\alpha_{1} t\right)$ will be much greater than that of $\exp \left(\alpha_{2} t\right)$ after a certain period of operation. Thus, Equation (13) can be reduced to

$$
C_{l}=C_{l 0} \beta_{1} \exp \left(\alpha_{1} t\right)
$$

From Equation (18), we know that $\alpha_{1}$ is the slope of a straight line when we plot $\ln C_{l}$ versus $t$.

Since $m, V_{l}, G$, and $V_{s}$ are known, the mass transfer coefficient can be calculated using the following equation, which is obtained by rearranging Equation (16):

$$
K_{s} a=-\frac{\alpha_{1}\left(1+\alpha_{1} V_{s} / G\right)}{m\left[\left(\alpha_{1} V_{s} / G\right)+1\right]+\alpha_{1} V_{l} / G}
$$

\section{Experimental Section}

Extraction experiments were performed in a $1.3 \mathrm{dm}^{3}$ semibatch extractor. The flow diagram of the experimental setup is shown in Figure 2, which is essentially the same as that used by Tai et al. $(2000,2001)$. The system was mainly composed of three parts: (1) a feeding system, (2) a pressurized extractor with temperature control,

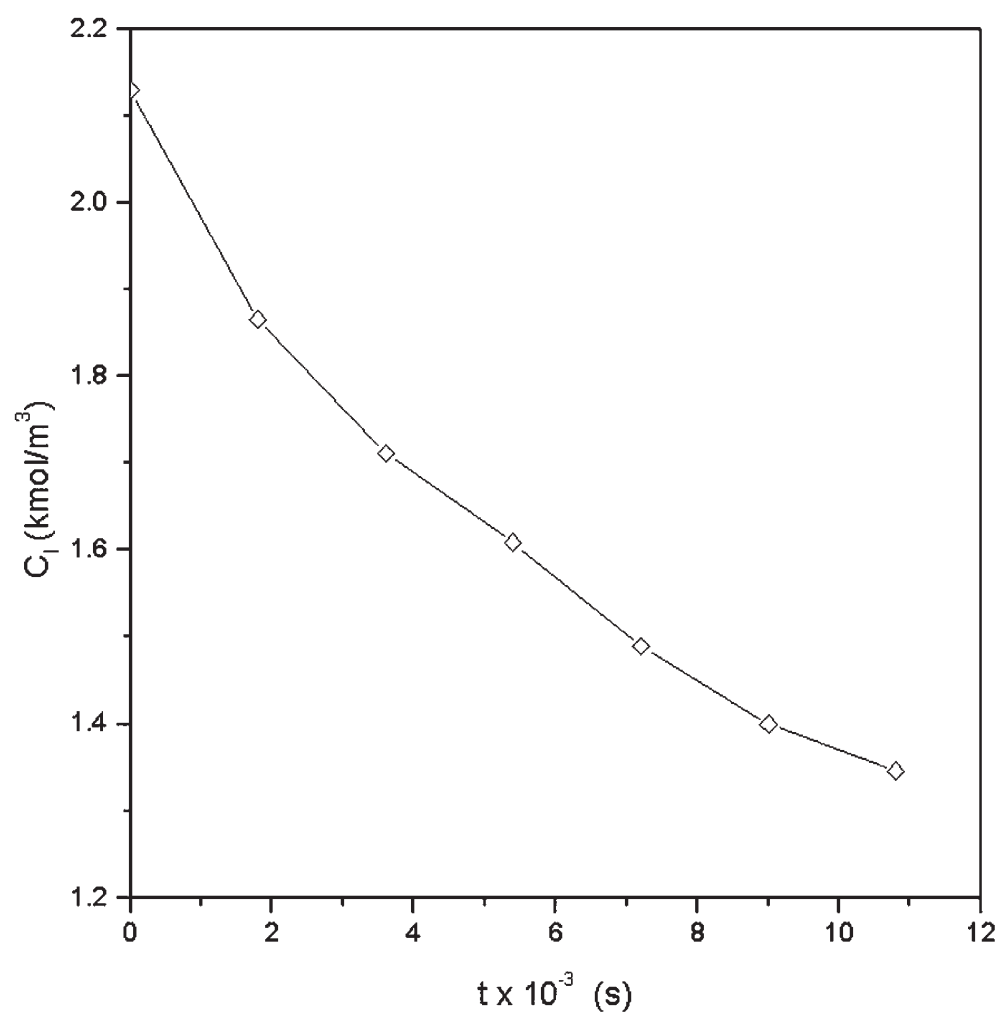

Figure 3. Ethanol concentration profile of liquid phase for run number 12. Operating conditions: temperature, $50^{\circ} \mathrm{C}$; superficial velocity, $1.25 \times 10^{-4} \mathrm{~m} / \mathrm{s}$; agitation rate, $8.3 \mathrm{~Hz}$; pressure, 13.6 MPa. 
and (3) a $\mathrm{CO}_{2}$ feed rate measurement system. The feeding system consisted of a $\mathrm{CO}_{2}$ cylinder, a cooler for preventing liquid $\mathrm{CO}_{2}$ from vaporizing, a piston pump (Milton Roy) for feeding liquid $\mathrm{CO}_{2}$, and a preheater. The extraction vessel was equipped with an agitator, a coil, a pair of viewing windows, and a sampling valve (Rheodyne, model 7010), and it was wrapped with heating tape for the purpose of temperature control. The measuring system consisted of a metering valve for controlling the depressurization rate and a dry test meter for measuring the $\mathrm{CO}_{2}$ flow rate. The metering valve had to be heated; otherwise, clogging could occur due to the solidification of $\mathrm{CO}_{2}$ during depressurization.

At the beginning of an experimental run, a volume of $0.8 \mathrm{dm}^{3}$ aqueous solution of $10 \mathrm{wt} \%$ ethanol was charged into the extractor. Then, $\mathrm{CO}_{2}$ (industrial grade with a purity of $99.5 \%$, containing 0.25 molar ppm $\mathrm{H}_{2} \mathrm{O}$ ) was pumped into the vessel until the vessel pressure reached the desired value. At this moment, the outlet valves were opened and the metering valve was adjusted to keep the vessel pressure constant; then, agitation was started. The volume hold up of $\mathrm{SC}^{\mathrm{CO}_{2}}$ was about $38 \%$ of the extractor volume. The $\mathrm{SC} \mathrm{CO}_{2}$ was then passed through the metering valve to reduce its pressure and flow and through a cold trap to remove ethanol and water. Then, the dry test meter recorded the amount of $\mathrm{CO}_{2}$. A liquid sample of $5 \mathrm{~mL}$ was removed from the extractor once every 30 minutes, and the concentration of the solution was analyzed with a gas chromatograph (Shimadzu, model GC-14A), using Porapak $\mathrm{Q}$ packing material and a flame onization detector (FID).



Figure 4. Logarithmic plot of Equation (18) for run number 12. 


\section{Results and Discussion}

In this study, experiments on extracting ethanol from aqueous solution were performed at $50^{\circ} \mathrm{C}$ under different $\mathrm{CO}_{2}$ flow rates, agitation rates, and system pressures. A temperature of $50^{\circ} \mathrm{C}$ was chosen because the mass transfer rate was previously found to increase with temperature (Brunner and Kreim, 1986), and because $50^{\circ} \mathrm{C}$ was about the highest temperature we could obtain in our system. Experimental data reported in this study are the average of two runs and are within a $10 \%$ difference.

\section{Determination of the Mass Transfer Coefficient}

A typical concentration profile of ethanol in aqueous phase is shown in Figure 3, in which the ethanol concentration decreases with time. According to Equation (18), a plot of $\ln C_{l}$ against $t$ will give a straight line with a slope of $\alpha_{1}$. Such a plot is shown in Figure 4, with a correlation coefficient of 0.98 . Then, after $\alpha_{1}$ is substituted into Equation (19), the mass transfer coefficient, $K_{s} a$, can be determined. Once the value of $K_{s} a$ is available, it can be used to check the assumption that neglects the second term on the right-hand side of Equation (13). $K_{s} a$ is substituted into Equations (11)

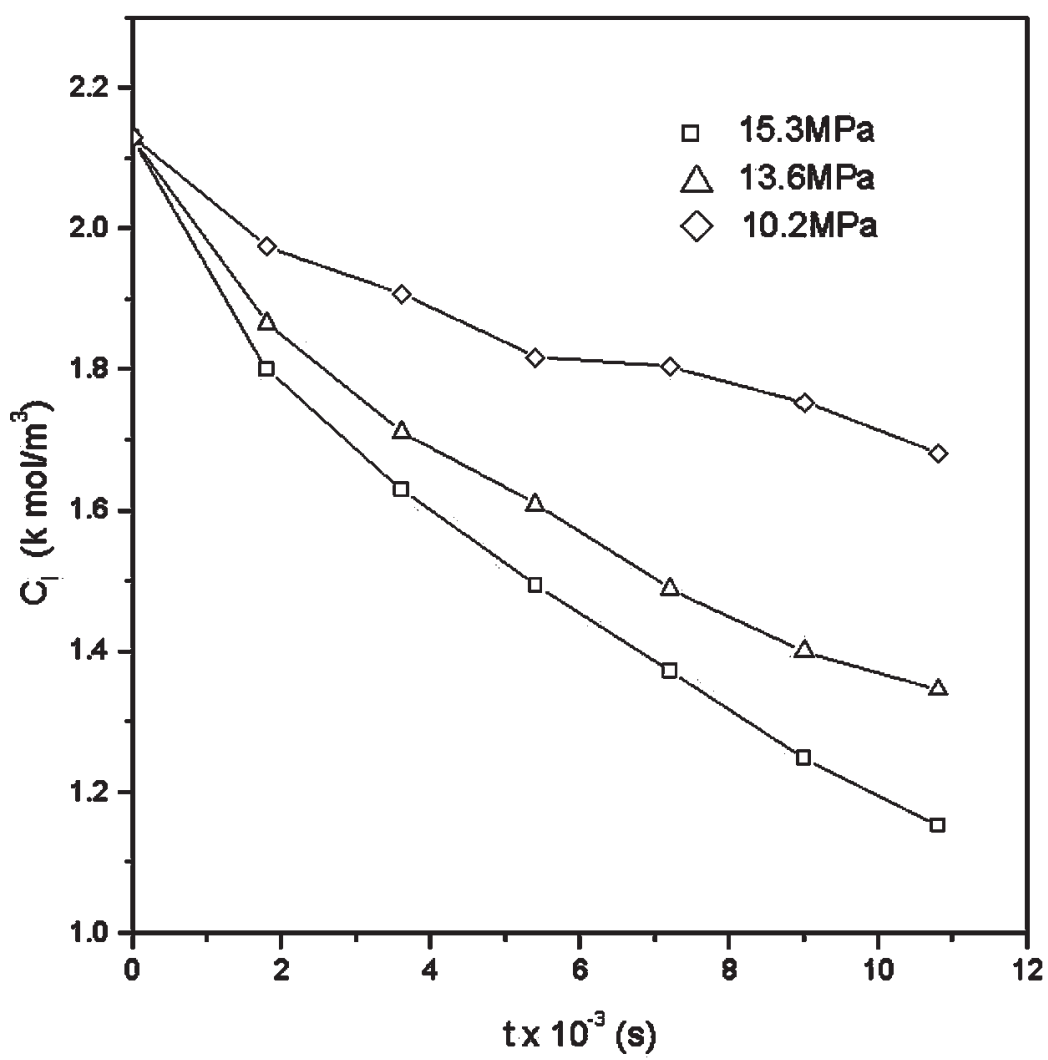

Figure 5. Pressure effect on the extraction rate. Operating conditions: temperature, $50^{\circ} \mathrm{C}$; superficial velocity, $1.25 \times 10^{-4} \mathrm{~m} / \mathrm{s}$; agitation rate, $8.3 \mathrm{~Hz}$. 
and (12) to calculate $q_{1}$ and $q_{2}$, and then $\alpha_{1}$ and $\alpha_{2}$ are determined as follows: $\alpha_{1}=-4.09 \times 10^{-5} \mathrm{~s}^{-1}$ and $\alpha_{2}=-1.81 \times 10^{-2} \mathrm{~s}^{-1}$. Then the magnitudes of the two terms on the right-hand side of Equation (13) can be compared. For example, $\exp \left(\alpha_{1} t\right)=226 \exp \left(\alpha_{2} t\right)$ at $t=300 \mathrm{~s}$. Thus, the assumption that neglects $\beta_{2} \exp \left(\alpha_{2} t\right)$ is reasonable.

\section{Effect of Pressure on the Mass Transfer Coefficient}

With the operating temperature and $\mathrm{CO}_{2}$ superficial velocity fixed at $50^{\circ} \mathrm{C}$ and $1.25 \times 10^{-4} \mathrm{~m} / \mathrm{s}$, the pressure effect on the mass transfer rate was investigated at three agitation rates, i.e., 8.3, 11.7, and $15.0 \mathrm{~Hz}$. Figure 5 shows the ethanol concentration profile of the liquid phase when extraction was performed at 10.2, 13.6, and 15.3 $\mathrm{MPa}$ under an agitation rate of $8.3 \mathrm{~Hz}$. The extraction rate was higher under higher pressure. Using the technique previously described, the mass transfer coefficients were determined and are plotted in Figure 6. It is clear that the mass transfer coefficient increased with increasing pressure and that the agitation rate was less influential than pressure on the mass transfer rate.

The effect of pressure on the mass transfer rate is a complicated problem. When the pressure increases, the properties of both phases will change. Some changes turn

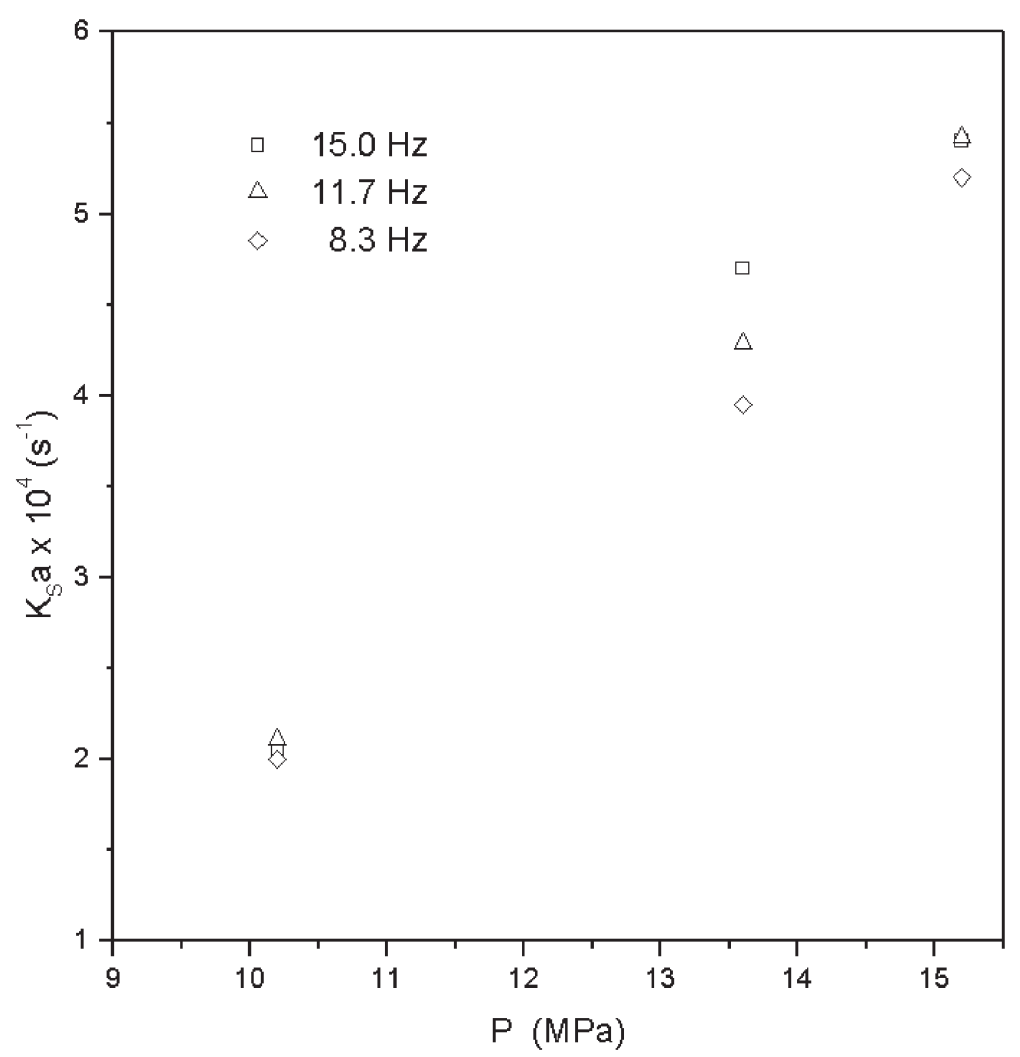

Figure 6. Pressure effect on the mass transfer coefficient for three agitation rates. 
out to be in favor of the mass transfer rate, but others have the opposite effect. Although the system property data of water/ethanol/SC $\mathrm{CO}_{2}$ are not sufficient to reveal the pressure effect, it is our intention to explain it based on the following arguments.

Mehta and Sharma (1970) investigated the effect of surface tension on the interfacial area in an agitated gas-liquid contactor. They concluded that a system with lower surface tension (carbon dioxide/water/monoethanolamine) possesses a higher interfacial area, i.e., smaller gas bubbles dispersed in the liquid, than does a system with higher surface tension (carbon dioxide/butanol/monoethanolamine). This is consistent with a correlation presented by McCabe et al. (2001), although it was not derived under supercritical conditions. In our system, the solubility of $\mathrm{CO}_{2}$ in water increased with increasing pressure, thus causing the surface tension to decrease. The lower surface tension resulted in a larger interfacial area due to the formation of smaller bubbles. Therefore, the interfacial area, $a$, increased with increasing pressure. At higher pressure, on the other hand, the viscosity of the supercritical phase will increase (Stephan and Lucas, 1979), and the diffusivity of ethanol might decrease based on the results obtained for other systems (such as naphthalene and caffeine in supercritical $\mathrm{CO}_{2}$ ) (Feist and Scheider, 1982); both will cause $K_{s}$ to decrease. It is conjectured that the effects of diffusivity and viscosity

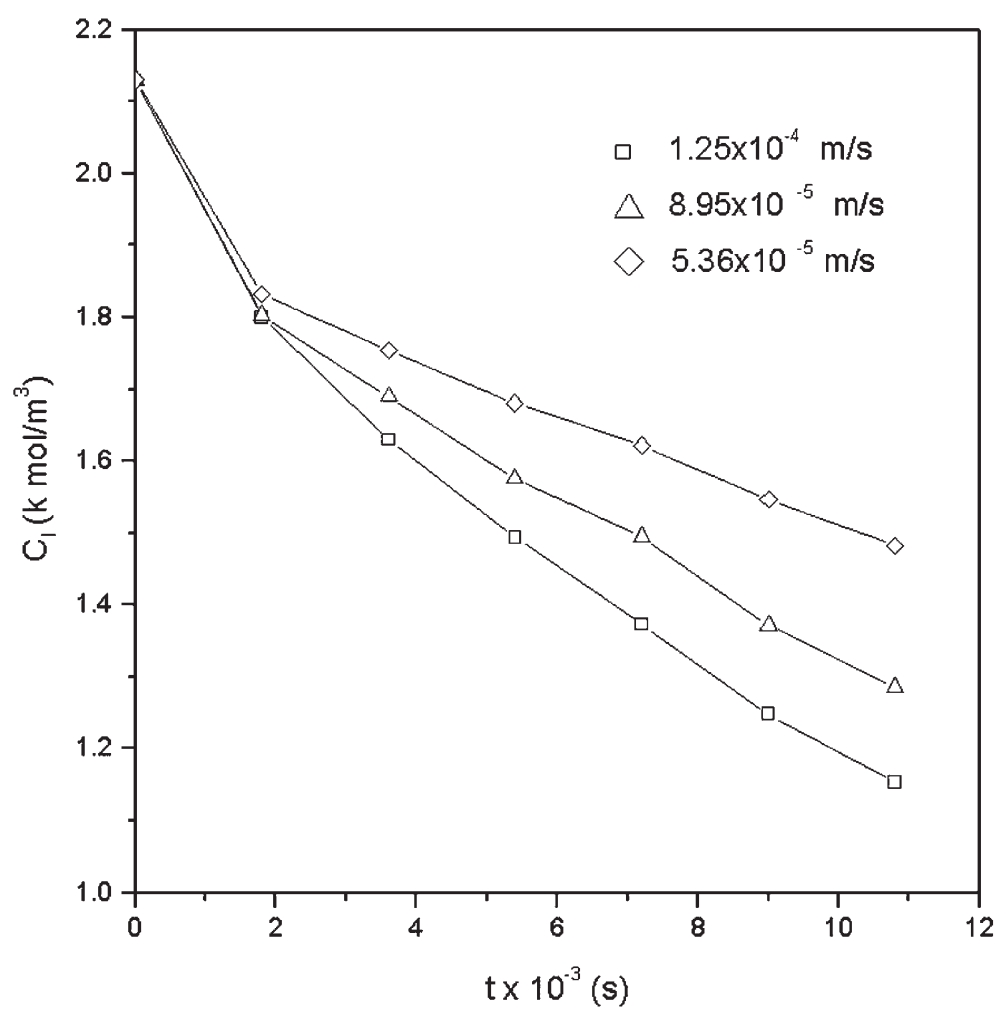

Figure 7. Effect of the $\mathrm{CO}_{2}$ superficial velocity on the extraction rate. Fixed operating conditions: temperature, $50^{\circ} \mathrm{C}$; pressure, $15.3 \mathrm{MPa}$; agitation rate, $8.3 \mathrm{~Hz}$. 
are less important than the effect of surface tension. As a result, the mass transfer coefficient, $K_{s} a$, increases at higher pressures.

\section{Effect of $\mathrm{CO}_{2}$ Superficial Velocity}

The effect of the $\mathrm{CO}_{2}$ superficial velocity on the extraction rate of ethanol was investigated for three levels of pressure, i.e., 10.2, 13.6, and 15.3 MPa. A typical result shown in Figure 7 for $15.3 \mathrm{MPa}$ indicates that the extraction rate increased with an increase in the $\mathrm{CO}_{2}$ superficial velocity, defined as $\left(\mathrm{CO}_{2}\right.$ volumetric flow rate)/ (cross section area of extractor), which varied here from $5.36 \times 10^{-5}$ to $1.25 \times 10^{-4} \mathrm{~m} / \mathrm{s}$. In addition, the estimated mass transfer coefficients are plotted in Figure 8. The mass transfer coefficient increased with an increase in the $\mathrm{CO}_{2}$ superficial velocity for all three levels of pressure. These findings can be explained by using the results reported by Oyevaar et al. (1991), assuming that the increase in the mass transfer coefficient is due to an increase in the interfacial area between the $\mathrm{SC} \mathrm{CO}_{2}$ bubbles and the aqueous phase. They investigated the $\mathrm{CO}_{2}$ superficial velocity and pressure effects on the interfacial area in a mechanically agitated gas-liquid contactor operated at pressures up to $8.0 \mathrm{MPa}$. A positive influence of pressure on the interfacial area was observed for higher $\mathrm{CO}_{2}$ superficial velocity and higher pressure.

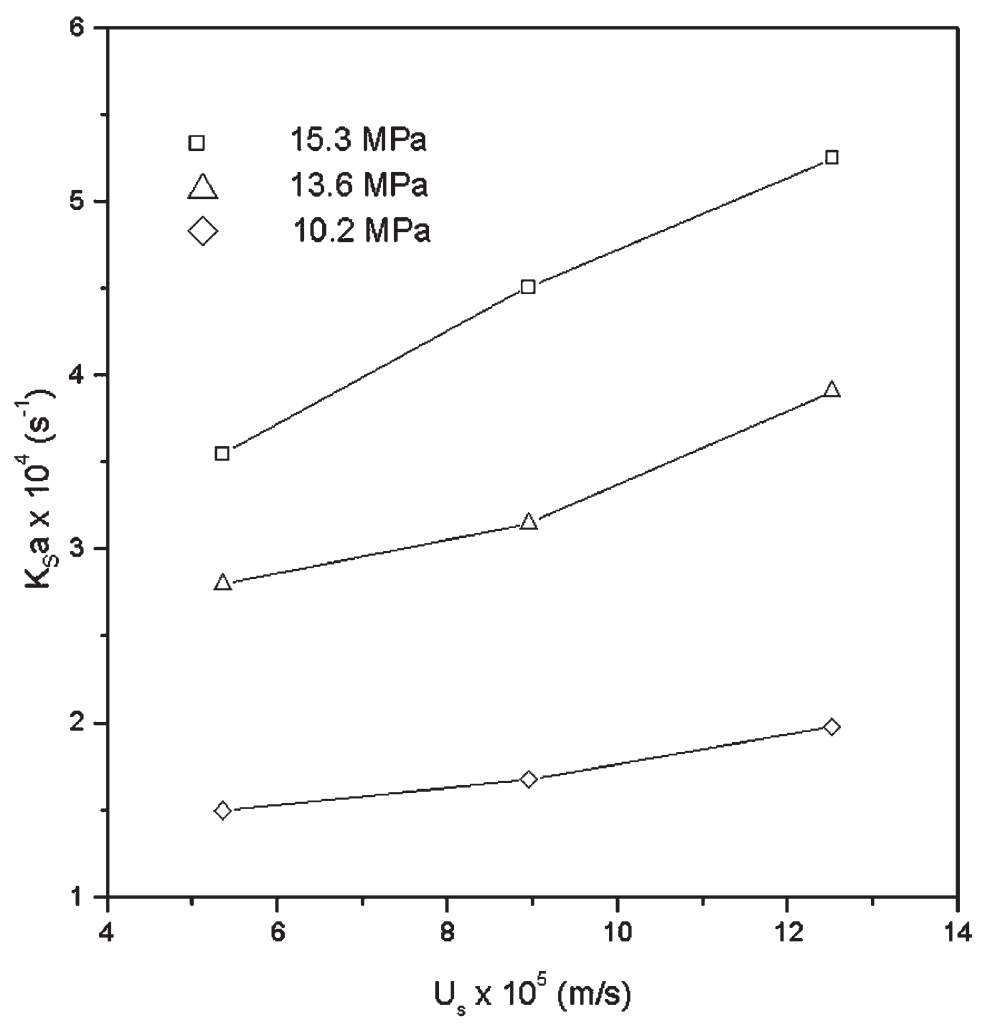

Figure 8. Effect of the superficial velocity on the mass transfer coefficient for various pressures. Fixed operating conditions: temperature, $50^{\circ} \mathrm{C}$; agitation rate, $8.3 \mathrm{~Hz}$. 


\section{Effect of Agitation Rate}

Three agitation rates were tested to determine the effect of agitation on the mass transfer coefficient. In Figure 9, the mass transfer coefficient is plotted against the agitation rate at various $\mathrm{CO}_{2}$ superficial velocities. The mass transfer coefficient increased with increasing agitation rate; however, the agitation rate had no effect at the highest $\mathrm{CO}_{2}$ velocity, $1.25 \times 10^{-4} \mathrm{~m} / \mathrm{s}$. This phenomenon can be explained using the concept of the minimum agitation rate proposed by Westerterp et al. (1963), i.e., the impeller tip velocity must exceed the gas rising velocity a certain number of times in order for all the big gas bubbles to be broken up into small bubbles. Using a chemical reaction method to estimate the interfacial area created by an impeller in a gas-liquid contactor, they found that the interfacial area increased as the agitation rate increased and was not influenced by the gas flow rate when the agitation rate was higher than the minimum agitation rate. On the other hand, the interfacial area remained constant when the agitation rate was lower than the minimum agitation rate. Since the minimum agitation rate increased as $\mathrm{CO}_{2}$ flow rate increased, the agitation rates studied in our experiment may have been below the minimum value for the highest $\mathrm{CO}_{2}$ superficial velocity, $1.25 \times 10^{-4} \mathrm{~m} / \mathrm{s}$. The interfacial area and, thus, the mass transfer coefficient remained constant. For the lowest superficial velocity, $5.36 \times 10^{-5} \mathrm{~m} / \mathrm{s}$, the agitation rate, $8.3 \mathrm{~Hz}$, exceeded the

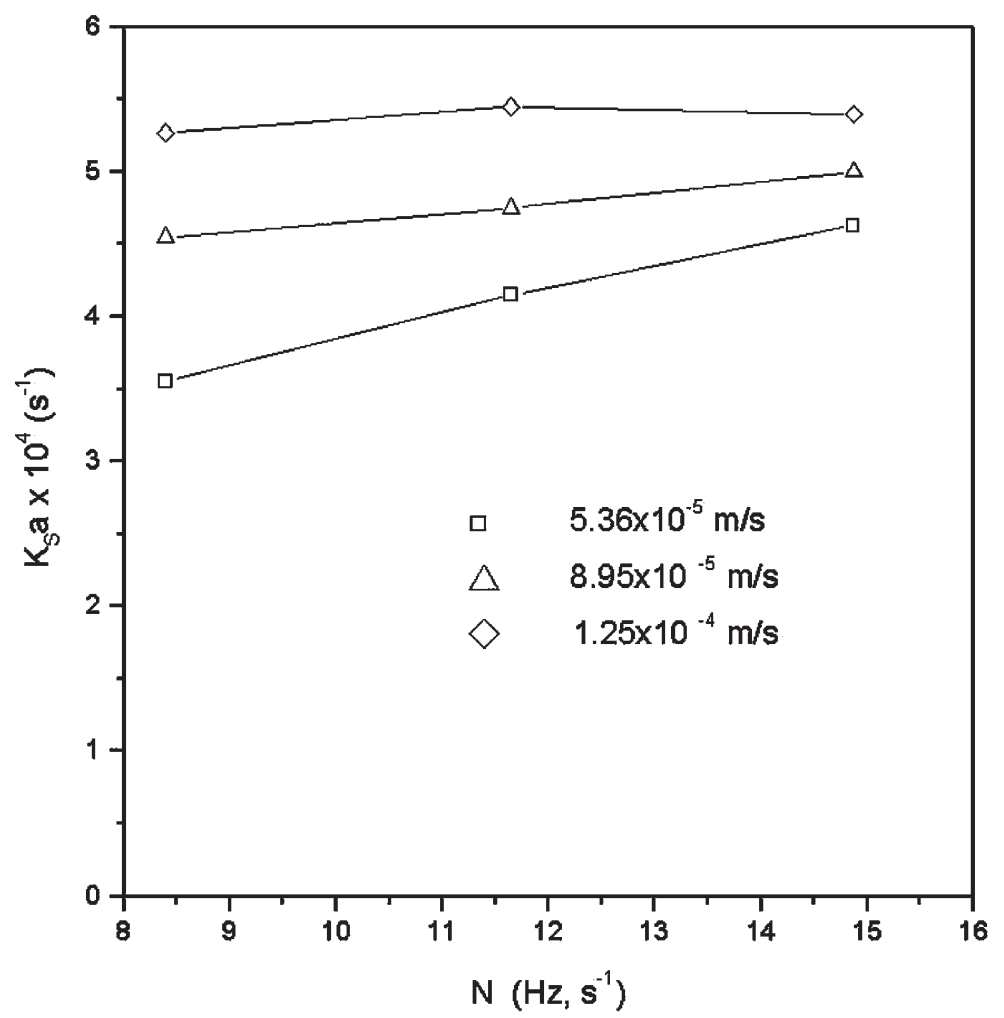

Figure 9. Effect of the agitation rate on the mass transfer coefficient for various $\mathrm{CO}_{2}$ superficial velocities. Other operating conditions: temperature, $50^{\circ} \mathrm{C}$; pressure, $15.3 \mathrm{MPa}$. 




Figure 10. Concentation of ethanol recovered in the collector.

minimum value, thus, the interfacial area or mass transfer coefficient increased as the agitation rate increased.

\section{Concentration of Recovered Ethanol}

The starting materials for this experiment contained $10 \mathrm{wt} \%$ ethanol. Under various operating conditions, the concentration of ethanol recovered from the collector after 180 minutes of operation reached $50 \mathrm{wt} \%$. Typical results are shown in Figure 10 for the two $\mathrm{CO}_{2}$ superficial velocities. The general trend observed in the figure indicates that the higher the pressure and velocity, the higher the concentration of recovered ethanol. The recovered concentration of ethanol was always less than the theoretical value estimated from equilibrium concentration, which is higher than $90 \mathrm{wt} \%$ (McHugh and Krukonis, 1986). It is assumed that the supercritical $\mathrm{CO}_{2}$ phase did not reach equilibrium or that perhaps some of the extracted ethanol was carried out of the collector by the depressurized $\mathrm{CO}_{2}$ gas and lost to the atmosphere.

\section{Conclusions}

With a starting material of $10 \mathrm{wt} \%$ aqueous solution, when supercritical $\mathrm{CO}_{2}$ was used as a solvent for extracting ethanol from an aqueous solution in a stirred vessel operated in a semibatch mode, the concentration of recovered ethanol reached 
$50 \mathrm{wt} \%$. The mass transfer coefficient of the extraction process increased with increasing pressure, $\mathrm{CO}_{2}$ superficial velocity, and agitation rate. The increase in the extraction rate was mainly due to an increase in the interfacial area between the $\mathrm{SC} \mathrm{CO}_{2}$ bubbles and the aqueous phase.

\section{Acknowledgment}

The authors gratefully acknowledge the financial support provided by the National Science Council of the Republic of China.

\section{Nomenclature}

A $\quad G / V_{s}+\left(V_{l} / V_{s}\right) K_{s} a$ as defined in Equation (10), $1 / \mathrm{s}$

a interfacial area, $\mathrm{m}^{2} / \mathrm{m}^{3}$

$C_{l} \quad$ concentration of ethanol in liquid phase, $\mathrm{k} \mathrm{mol} / \mathrm{m}^{3}$

$C_{l i} \quad$ interfacial concentration of ethanol in liquid phase, $\mathrm{k} \mathrm{mol} / \mathrm{m}^{3}$

$C_{l 0} \quad$ initial concentration of ethanol in liquid phase, $\mathrm{k} \mathrm{mol} / \mathrm{m}^{3}$

$C_{l}(s)$ transformed $C_{l}, \mathrm{~s} \cdot \mathrm{k} \mathrm{mol} / \mathrm{m}^{3}$

$C_{r} \quad$ ethanol concentration recovered in the collector, $\mathrm{wt} \%$

$C_{s} \quad$ concentration of ethanol in $\mathrm{SC} \mathrm{CO}_{2}$ phase, $\mathrm{k} \mathrm{mol} / \mathrm{m}^{3}$

$C_{s i} \quad$ interfacial concentration of ethanol in supercritical phase, $\mathrm{k} \mathrm{mol} / \mathrm{m}^{3}$

$C_{s}(s)$ transformed $C_{s}, \mathrm{~s} \cdot \mathrm{k} \mathrm{mol} / \mathrm{m}^{3}$

$C_{s}^{*} \quad m C_{l}$, ethanol concentration of supercritical phase in equilibrium with the liquid phase concentration, $\mathrm{k} \mathrm{mol} / \mathrm{m}^{3}$

$G \quad$ volumetric flow rate of $\mathrm{SC} \mathrm{CO}_{2}, \mathrm{~m}^{3} / \mathrm{s}$

$K_{s} a \quad$ overall mass transfer coefficient, $1 / \mathrm{s}$

$m \quad$ equilibrium constant

$N \quad$ mixing rate, $\mathrm{Hz}$

$P \quad$ pressure, $\mathrm{MPa}$

$q_{1} \quad K_{s} a m+G / V_{s}+\left(V_{l} / V_{s}\right) K_{s} a$ as defined in Equation (11), $1 / \mathrm{s}$

$q_{2} \quad K_{s} a m\left(G / V_{s}\right)$ as defined in Equation (12), $1 / \mathrm{s}^{2}$

$s \quad$ Laplace variable, $1 / \mathrm{s}$

$t \quad$ time, $\mathrm{s}$

$U_{s} \quad$ superficial velocity of $\mathrm{SC} \mathrm{CO}_{2}, \mathrm{~m} / \mathrm{s}$

$V_{l} \quad$ volume of liquid phase in the extractor, $\mathrm{m}^{3}$

$V_{s} \quad$ volume of $\mathrm{SC} \mathrm{CO}_{2}$ in the extractor, $\mathrm{m}^{3}$

$\alpha_{1}=\left(-q_{1}+\sqrt{q_{1}^{2}-4 q_{2}}\right) / 2$ as defined in Equation (16), $1 / \mathrm{s}$

$\alpha_{2}=\left(-q_{1}-\sqrt{q_{1}^{2}-4 q_{2}}\right) / 2$ as defined in Equation (17), $1 / \mathrm{s}$

$\beta_{1}=\left(\alpha_{1}+A\right) /\left(\alpha_{1}-\alpha_{2}\right)$, dimensionless

$\beta_{2}=\left(\alpha_{2}+A\right) /\left(\alpha_{2}-\alpha_{1}\right)$, dimensionless

\section{References}

Bernard, L., Keller, A., Barth, D., and Perrut, M. (1991). Separation of ethanol from aqueous solutions by supercritical carbon dioxide: Comparison between simulations and experiments, in Proceedings of the 2nd International Symposium on Supercritical Fluids, 394 397, Boston. 
Brunner, G. and Kreim, K. (1986). Ger. Chem. Eng., 9, 246.

Etuk, B. R. and Murray, K. R. (1990). I. Chem. E. Symp. Ser., 119, 279.

Feist, R. and Schneider, G. M. (1982). Sep. Sci. Technol., 17, 261.

Larson, K. and Wiencek, J. M. (1993). Ind. Eng. Chem. Res., 32, 2854.

Liu, H.-S. and Hsu, H.-W. (1990). Chem. Eng. Sci., 45, 1289.

McCabe, W. L., Smith, J. C., and Harriot, P. (2001). Unit Operations of Chemical Engineering, 6th ed., chap. 9, 238-285, McGraw-Hill, Taipei, Taiwan.

McHugh, M. and Krukonis, V. (1986). Supercritical Fluid Extraction: Principles and Practice, chap. 8, 117-142, Butterworths, Boston.

Mehta, V. D. and Sharma, M. M. (1970). Chem. Eng. Sci., 26, 461.

Oyevaar, M. H., Bos, R., and Westerterp, K. R. (1991). Chem. Eng. Sci., 46, 1217.

Puiggené, J., Larrayoz, M. A., and Recasens, F. (1997). Chem. Eng. Sci., 52, 195.

Riha, V. and Brunner, G. (2000). J. Supercrit. Fluids, 17, 55.

Stephan, K. and Lucas, K. (1979). Viscosity of Dense Fluids, 75-79, Plenum, New York.

Tai, C. Y., You, G.-S., and Chen, S.-L. (2000). J. Supercrit. Fluids, 18, 201.

Tai, C. Y., Huang, S.-C., Huang, M.-S., and Liu, H.-S. (2001). J. Chin. Inst. Chem. Eng., 32, 269.

Tan, C. S., Liang, S. K., and Liou, D. C. (1988). Chem. Eng. J., 38, 17.

Westerterp, K. R., van Dierendonck, L. L., and de Kraa, J. A. (1963). Chem. Eng. Sci., 18, 157. 
Copyright of Chemical Engineering Communications is the property of Taylor \& Francis Ltd. The copyright in an individual article may be maintained by the author in certain cases. Content may not be copied or emailed to multiple sites or posted to a listserv without the copyright holder's express written permission. However, users may print, download, or email articles for individual use. 